\title{
EVALUACION DE UN CONJUGADO ANTIRRABICO POR TITULACION EN DIFERENTES MICROSCOPIOS FLUORESCENTES
}

\author{
O. P. LARGHI (1), O. OLIVA-PINHEIRo (2) y E. GONZALEZ-LUARCA (3)
}

\begin{abstract}
R E S U M E N
En cinco laboratorios se titulo una partida de conjugado antirrábico para inmunofluorescencia con microscopios de tres marcas distintas, equipados con diferentes accesorios. Los títulos obtenidos variaron entre $<1: 4$ y 1:64, dependiendo de los accesorios utilizados. Estos resultados ponen de relieve la necesidad de titular los conjugados en cada laboratorio. Se mencionam los inconvenientes que pueden ocasionar la distribución del reactivo diluido de acuerdo con el título obtenido por el productor, o mezclado con suspensiones de cerebro de ratones normales e infectados con virus rábico.
\end{abstract}

UNITERMOS: Raiva - Imunofluorescência - Sorologia - Teste de qualidade diagnóstica.

\section{N T R O D U G $\vec{A} O$}

El diagnóstico de la rabia por inmunofluorescencia (IF) puede ser muy eficiente $1,6,8,11,12$ siempre que se tomen ciertas precauciones, tales como un muestreo adecuado de los especímenes de tejido nervioso ${ }^{6}$, la alineación correcta del microscopio ${ }^{9}$ y la estandarización apropiada del conjugado para IF ${ }^{10}$. Esta estandarización es esencial para la eficiencia del método. En algunos sistemas, los títulos por IF de los conjugados guardan relación con los títulos obtenidos por otras técnicas serológicas ${ }^{4}$. Este no es el caso cuando se comparan los títulos de los conjugados antirrábicos obtenidos por IF y por neutralización 13,17 . Por ello, para estandarizar el conjugado antirrábico, es necesario titularlo en el sistema antígeno-anticuerpo correspondiente con el microscopio que se empleará en las pruebas de rutina. Al hacerlo, se determina el título y la especificidad de los anticuerpos 19.

A pesar de que se han publicado algunos trabajos sobre la estanđarización de la IF para el diagnóstico de la rabia usando un analizador de espectro ${ }^{16}$, este equipo no se encuentra comúnmente en los laboratorios, en los que se estandariza el conjugado basándose en una graduación visual.

Este tipo de lectura puede ser subjetivo, si bien se ha comprobado que los resultados obtenidos por personal con experiencia son muy reproducibles 3,7 . No obstante, los técnicos con poca experiencia suelen adjudicar la clasificación más alta ( 4 cruces) a la intensidad máxima que observan con un conjugado dado, aunque esa intensidad no sea lo suficientemente brillante para merecer esa clasificación.

Si bien hay gran número de factores que tienen una relación directa con el título de los conjugados, como por ejemplo, los accesorios de los microscopios ${ }^{15}$, con frecuencia los técnicos no los toman en cuenta y usan el reactivo en la dilución que sugiere el productor. En este

(1) OPS/OMS, Centro Panamericano de Zoonosis, Buenos Aires, Argentina

Dirección Actual: (1) OMS/Organización Panamericans de la Salud, Casilla 2117, Lima, Peru

(2) Fundaçăo Oswaldo Cruz, Rio de Janeiro, Brasil

(3) OMS/Organización Panamericana de la Salud, Brasilia, Brasil 
LARGHI, O. P.; OLIVA-PINHEIRO, O. \& GONZALEZ-LUARCA, E. - Evaluación de un conjugado antirrabico por titulación en diferentes microscopios fluorescentes. Rev. Inst. Med. trop. Sä0 Paulo 28:2-5, 1986.

trabajo presentamos los resultados obtenidos al titular una partida de conjugado antirrábico en cinco laboratorios con microscopios de distintas marcas equipados con diferentes accesorios.

Conjugado - Este reactivo se preparó con suero antirrábico de hamsters $\mathrm{e}$ isotiocianato de fluoresceina, de acuerdo con el método descrito anteriormente 11.

Titulación del conjugado - El conjugado se tituló coloreando impresiones negativas $\mathrm{y}$ positivas para rabia de cerebros de ratones, con diluciones dobles del reactivo preparadas en suspensiones de cerebros de ratones normales y de ratones infectados con el virus CVS. Para cada dilución se evaluaron tres factores:
1) la cantidad de antígeno observado; 2) la intensidad de la tinción específica y 3) la intensidad de la tinción inespecifica. Se consideró como título del conjugado la dilución que produjo una intensidad especifica de alto brillo, que coloreó todo el antígeno disponible en las impresiones y que no presentó tinción de fondo 0 inespecifica 7 . Las personas responsables del diagnóstico de la rabia en cada laboratorio realizaron estas titulaciones con la asistencia de uno de nosotros.

El conjugado se tituló en cinco laboratorios con tres marcas de microscopios. Las características de los tubos, objetivos, oculares, filtros primarios y tipo de iluminación empleados con cada microscopio se presentan en el Quadro I.

C UADRO I

Características de los microscopios de fluorescencia usados para titular una partida de conjugado

\begin{tabular}{|c|c|c|c|c|c|c|c|c|c|c|}
\hline \multirow[t]{2}{*}{ Laboratorio } & \multicolumn{2}{|c|}{ Mictoscopios } & \multicolumn{2}{|c|}{ Oculares } & \multicolumn{2}{|c|}{ Objetivos } & \multirow{2}{*}{$\begin{array}{l}\text { Filtros } \\
\text { Primarios }\end{array}$} & \multicolumn{3}{|c|}{ Fuente de luz } \\
\hline & Marca & Tubo & Aumento & $A N$ & Aumentos & Inmersión & & Tipo & & Lámpara \\
\hline $1 \mathbf{a}$ & A & Binocular & 10.0 & 1.30 & 40 & Si & Azul & Epi & & HBO50 \\
\hline $1 b$ & $"$ & " & 10.0 & 1.30 & 40 & " & UV & $"$ & & $"$ \\
\hline 2 & B & Monocular & 6.3 & 1.20 & 95 & $"$ & $"$ & Trans & & HBO-200 \\
\hline $\mathbf{3 a}$ & C & Binocular & 8.0 & 0.65 & 40 . & No & $"$ & $"$ & & $"$ \\
\hline $3 b$ & $"$ & " & 8.0 & 1.00 & 40 & Sí & $"$ & $"$ & & $"$ \\
\hline $3 \mathrm{c}$ & $"$ & $"$ & 8.0 & 0.65 & 40 & No & Azul & $"$ & .. & $"$ \\
\hline 4 & $"$ & $"$ & 8.0 & 1.30 & 100 & $\mathbf{S i}$ & $"$ & Epi & & HBO-50 \\
\hline 5 & $"$ & $"$ & 8.0 & 1.25 & 100 & $"$ & $"$ & " & & Halógeno 100 \\
\hline
\end{tabular}

AN $=$ apertura numérica; UV $=$ luz ultravioleta; Epi $=$ epi-iluminación; Trans $=$ luz transmitida

En el Quadro II presentamos los títulos obtenidos en los laboratorios participantes en el estudio. Estos títulos variaron entre $<1: 4$ y 1:64, dependiendo de las características del microscopio utilizado.

C U A D R II

Títulos obtenidos con una partida de conjugados en diferentes microscopios

\begin{tabular}{cc}
\hline Laboratorio & Titulo $\left.{ }^{*}\right)$ \\
\hline $1 \mathrm{a}$ & $1: 32$ \\
$1 \mathrm{~b}$ & $1: 4$ \\
2 & $1: 4$ \\
$3 \mathrm{a}$ & $<1: 4$ \\
$3 \mathrm{~b}$ & $1: 4$ \\
$3 \mathrm{c}$ & $1: 8$ \\
4 & $1: 64$ \\
5 & $1: 10$
\end{tabular}

(*) 3.4+ de intensidad especifica y cantidad de antigeno; $0+$ de tinción inespecifica

Hay once o doce factores que afectan el brillo del conjugado antirrábico: entre ellos se incluyen la luz ambiente, el ojo del operador, el antígeno, las anti-globulinas, el fluorocromo y los accesorios del microscopio 15. En nuestro caso, evaluamos nueve factores relacionados con el microscopio, los que produjeron una gran variación en los títulos ( $<1: 4$ a 1:64). Estas variaciones se observaron no solo entre laboratorios, sino también en un mismo laboratorio cuando se usaron distintos accesorios en el microscopio. Por ejemplo, la excitación con luz azul produjo mejores títulos que con la luz ultravioleta (UV) en los laboratorios 1 y 3 (3a y 3c). Ello se debió a que los derivados de la fluoresceína emiten fluorescencia más eficientemente cuando son excitados con luz azul que con luz UV ${ }^{14}$. Wachendorfer \& col.18 obtuvieron mejores títulos que los recomendados por los productores de conjugados cuando usaron luz azul en su microscopio. Apesar de ello, debe recordarse que la excitación con luz azul también produce mayor cantidad de tinción inespecífica con los antígenos incluidos en te- 
LARGHI, O. P.: OLIVA-PINHEIRO, O. \& GONZALEZ-LUARCA, E. - Evaluación de un conjugado antirrabico pos titulación en diferentes microscopios fluorescentes, Rev. Inst. Med. trop. Sāo Pallo 28:2-5, 1986.

jidos ${ }^{14}$, como es el caso de los virus. Con microscopios de la misma marca, en el laboratorio 4 que empleó lámpara de mercurio y objetivos de mayor apertura numérica, la fluorescencia fue más brillante que en el raboratorio 5. En microscopia, el brillo es directamente proporcional al cuadrado de la apertura numérica, pero inversamente proporcional al cuadrado de los aumentos 5 .

Habida cuenta de los resultados obtenidos, supongamos que el laboratorio 5 hubiera sido el productor del conjugado usado en este estudio y que hubiera informado un titulo de 1:10. Si el laboratorio 2 lo hubiera usado en esa dilución, habria tenido muchas posibilídades de obtener resultados negativos falsos en el diagnóstico de rutina, porque habría usado el conjugado demasiado diluido para su microscopio. Por otra parte, si el laboratorio 4 hubiera aplicado el mismo criterio, las posibilidades de que obtuviera tinción inespecifica y resultados positivos falsos se habrian incrementado porque hubiera usado el conjugado dernasiado concentrado para su microscopio. Por ello, siempre hay que tener presente que los títulos que in. forma el productor del conjugado son solo una referencia para su posterior titulación en cada laboratorio.

La diferencia en los títulos de los conjugados obtenidos en este estudio pone de relieve la necesidad de realizar la titulación en cada laboratorio io y de no distribuir ios conjugados ya diluidos de acuerdo con el título obtenido por el prođuctor, ni mezclado con las suspensiones de cerebros de ratones normales $e$ infectados con virus rábico, como se hace en algunos laboratorios ${ }^{2}$. Otros Autores ${ }^{18}$, han 1lamado la atención sobre la inconveniencia de esta última prâctica.

\section{SUMMARY}

\section{Evaluation of a rabies conjugate by titration in different fluorescent microscopes}

A batch of antirabies fluorescence conjugate was titrated in five laboratories, with three different makers of microscopes, equipped with a variety of accesories. The titers ranged between $<1: 4$ and 1:64, depending on the accesories used. The results indicate the need for each laboratory to titrate the conjugate.
Also, the disadvantages of distributing the reagent diluted according to the titer obtained by the manufacturer, or mixed with the rabiesinfected and normal mouse brain suspensions, are discussed.

\section{REFERENCES}

I CARSKI, T. R.; WILSNACK, R. E. \& SIKES R. K. Pathogenesis of rabies in wildife. II. Fluorescent antibody studies. Amer. J. Vet Res. 23: 1048-1052, 1962.

2. CENTER FOR DISEASE CONTROL - Rabies Surveil. lance Roport. April-June 1974, p. 2, 1975.

3. CHERRY, W. B. - Eluorescence emission with special reference to standardization in immunofluorescence. En: HOLLOW, E. J. (ed.) Standardization of immupofluorescence. Oxford, Blackwell Scientific Publications, p. $127-135,1970$.

4. EELTKAMP. Y. E. W. - Titration of conjugates. En: HOLLOW, E. J. (ea.) Standardization of immunorluorescence. Oxford; Blaciswèll Scientific Publications. p. $189 \cdot 192,1970$.

5. GOLDMAN, M. - Fluorescent Artibods Methods. New York, Academic Press, 196B.

6. KISSLING, R. E. $\sim$ The fluorescent antibody test in rabies. En: BAER, G. M. (ed.) The natural history of rabies. New York, Academic Press., p. 401-416, 1975.

7. LARGHI, O. P. - Pruebs de anticuerpos fluorescentes para rabia. Centro Panamericano de Zoonosis OPS/OMS (Nota Técnica 8). Ramos Mejía, Argentina, 1975.

8. LARGHi, O. P.; GOYCOLEA, N. E.; CASADEI, C. J \& ZUCCON, B. J. E. - Comparación de la diagnosis clinica de la rabia con los métodos de laboratorio. Rev. Pasteur (Bs. As.) 4: 5.8, 1971.

9. LARGHL, O. P. \& JIMLNEZ CH., E. - Methods for accelerating the fluorescent antibody test for rabies diagnosis. Appl. Microblol. 21: 611-613, 1971.

10. LENNETTE; E. H. \& SCHMIDT, N. - Diagnostic procedures for viral, rickettsial and-chlamydial infection. 5th ed. Washington, D. C., American. Public Health Association. 1979.

11. LENNETTE, E. H.; WOODIE, J. D.; NAKAMURA, K. \& MAGOFFIN, R. L. - The diannosis of rabies by fluorescent antibody method (FRA) emploiyng immune hamster serum, HIth. Lab. Sci. 2: 24-34, 1965.

12. MCQUEEN, J. L.; LEWIS A. L. \& SCHNEIDER, N. J. - Rabies diagnosis by fluorescent antibody. I. Its evaluation in a public health laberatory. Amer. J. Pub. Hith. 50: 1743-1752, 1962. 
LARGHI, O. P.; OIIVA-PINHEIRO, O. \& GONZALEZ-LUARCA, E. - Eraluación de un conjugado antirrabica por titulacion en diferentes microscopios fluorescentes, Rev. Inst. Med. trop. Säo Paulo 28:2-5, 1986.

13. NADEL, M. K. \& CARSKI, T. R. - Investigation into factors influencing staining intensities of rabies immunofluorescent conjugates. Hith. Lab. Sci. 1: 60-64, 1964.

14. NAIR, R. C. - Fluorescent protein tracing, 3rd ed. Baltimore, Williams and Wilkins Company, 1969.

15. TOMKINSON, A. B. - Ilumination I. En: HOLLOW, E. J. (ed). Standardization of immunofluorescence. Oxford, Blackwell Scientific Publications, 1970, p. 5-10.

16. TRIMARChI, C. V. \& DEBBIE, J. G. - Standardization and quantitation of immunofluorescence in the rabies fluorescent antibody test. Appl. Microbiol. 24: 609-612, 1972.
17. TZIANOBOS, T.; HEBHRT G. A. \& WHITE, L. A: Preparation of rabies fluorescein isothiocyanate-labeled immune globulin from mouse hyperimmune ascetic fluids. J. Clin. Microbiol. 3: 609-612, 1976.

18. WACHENDORFER, G.: FRIEDERICH H. \& FROST, J. W. - Untersu Chungen uber die Eignun verschledener Konjugate zur fluoreszenzserologischen Diagnostik der Tolwutt. Dtsch. TierarztI. Wschr. 88: 171-174, 1981.

19. YAMAMOTO, A. \& KAWAMURA, A. - Assessment of conjugates. En: HOLLOW, E. J. (ed). Standardization of immunofluorescence. Oxford, Blackwell, Scientific Publications, 1970, p. 181-183.

Recebido pars publicaçäo em 20-12-1984. 